\title{
Labor efficiency, government spending and productivity nexus based on panel ARDL approach: Evidence from selected European countries
}

\section{Wen Xuezhou}

Jiangsu University

Rana Yassir Hussain ( $\nabla$ yassir.hussain@ue.edu.pk)

Jiangsu University https://orcid.org/0000-0002-6951-1322

Haroon Hussain

University of Sargodha

Muhammad Saad

National University of Computer and Emerging Sciences, Karachi Campus

Sikandar Ali Qalati

Jiangsu University

Shaibu Ali

Jiangsu University

\section{Technical Notes}

Keywords: Productivity, Labor Efficiency, Gross Earnings, Government Spending, HDI, Europe

Posted Date: September 9th, 2020

DOl: https://doi.org/10.21203/rs.3.rs-68485/v1

License: (1) This work is licensed under a Creative Commons Attribution 4.0 International License.

Read Full License 


\section{Abstract}

The current study advocates the role of efficient labor, average gross earnings per person, government spending, and quality of human life in defining the productivity of thirteen European countries. This study applied panel ARDL approach for data period ranging from 2001 to 2016. The results, in the long run, suggested that more efficient labor, increased gross earnings, and higher HDI causes higher productivity in the selected European countries. However, the results for the gross earnings were positive but insignificant. Government spending and inflation had a significant negative impact on productivity. These results suggest to keep inflation in check and limit the government expenditure to human development and to the productive uses in the selected countries.

\section{Introduction}

European nations are setting new benchmarks for human development and productivity in the world over the last many decades. They have a less but efficient workforce, better wage rates, caring governments, and better quality of life for masses in global comparison. The debate regarding fewer working hours, spending money on people, and a better quality of life is extending uniquely in the context of productivity. Researchers claim that an increase in productivity is achievable with fewer but handsomely paid working hours, long weekends, and a better quality of life (Brown et al., 2010; Brown, 2012; Collewet and Sauermann, 2017). The governments are assigned this responsibility to promote employment with a better life and enhanced productivity. The governments are equipped with public tax money to achieve these targets. One way to assess the role of governments is through institutional performance as institutions are representative of governments (Dias and Tebaldi, 2012). We propose that government spending on the public is a more direct approach that can contribute to productivity in either direction. However, many studies reported a negative association between government expenditure and growth (for example Afonso and Furceri, 2010; Romero-Avila and Strauch, 2008). Recently, Adnan et al. (2019) measured a significant negative impact of government expenditure in the long run on total factor productivity of South Asian countries except for Sri Lanka, for which they reported a positive effect of government expenditure on overall factor productivity. There should exist a linkage in composite sense between workforce efficiency, better earnings, quality of life, government spending, and productivity. The same question is under exploration in current research. Moreover, this research employs a panel autoregressive distributive lag approach to the panel data set of 13 European nations, which had aboveaverage productivity at the end of the year 2016, the last year of data in this study.

Many researches have linked population growth with economic growth, and the results are mixed. Economic growth is a general term, and it has many determinants. A more labor-intensive measure of growth is used in this study, termed as productivity instead of overall growth. We have scaled the gross domestic product (GDP) with total hours worked in respective countries in this analysis (similar to Blažys, 2020). A general perception is that more populous states have more working hands and thus the association of population with growth tested in various studies. The question arises what if the majority of people do not work as in many countries due to multiple reasons like high unemployment, financial 
crisis, etc. The allocation of limited resources over a vast population is impossible, which leads to a less skilled workforce, which in turn also causes harm to growth. It will be more conclusive if we use a measure that accounts for the workability of the population. Thus, we used the ratio of the total population with annual hours worked in our analysis, collectively termed as labor efficiency. A better wage system also contributes to the welfare and satisfaction of workers, and plenty of research also supports the notion that well-compensated labor also adds more to productivity (Baharin et al., 2020; Lalwani and Chakraborty, 2020). A better earnings system also attracts better workers and superior minds to the country that can be a cause of better productivity.

We also emphasize that expenditure on education, health, overall spending on the public in a welfare state and the quality of people's lives improve their productive skills. We used total government spending as percentage of GDP in the selected countries as a factor that may contribute to productivity. A standard indicator known as the human development index (HDI) is used to measure the quality of life (Roy and Mohanty, 2020). This research also controls the inflation effects, which contributes negatively to productivity as past evidence suggests in various studies (Bulman and Simon, 2020; Morvillier, 2020). Some studies also establish an insignificant association between inflation and productivity (Narayan and Smyth, 2009). Our study is structurally divided into four parts, as the next part II describes the study sample, variable construction, and the empirical models developed for data analysis purposes. Section III states empirical results. Part IV concludes the paper.

\section{Sample, Variable Description And Empirical Models}

A sample of 13 European countries is constructed subject to the availability of annual data from 2001 to 2016. The sample countries are selected based on the productivity above the average productivity in Europe. The data regarding population, hours worked, GDP and government spending are taken from Eurostat. The HDI data used from the United Nations Development Program (UNDP) and CPI data source is transparency international. The description of variables along with measurement technique is summarized in table 1.

Table 1 Variables, their measures, and assigned notations 
No. Variable

Measurement

Total Population/total hours worked

(A decreasing trend in this ratio depicts efficient labor and vice versa)

\begin{tabular}{llll}
\hline 2 & Gross Earnings & Annual earnings per person & GE \\
\hline 3 & $\begin{array}{l}\text { Government } \\
\text { Spending }\end{array}$ & Government Spending as a percentage of GDP & GS \\
\hline 4 & Quality of Life & Human development index used as proxy & HDI \\
\hline 5 & Inflation & Consumer price index used as proxy & CPI \\
\hline 6 & Productivity & Gross domestic product/total hours worked & PROD
\end{tabular}

The econometric approach to investigate the relationship among study variables should base on the nature and type of data. We are using panel data as it possesses the characteristics of both time series and cross-sections, and it has several advantages. It is suitable for a bigger sample size (Gujarati, 2003), controls for heterogeneity and multicollinearity, and has more freedom and efficiency as compared to time series and cross-sectional data (Baltagi, 2008). We preferred a dynamic regression model over static regression model. This study employs a pooled mean group or panel ARDL approach because it is appropriate for the studies with small sample size. This study includes 13 countries and 16 years, which is a relatively small sample compared to many studies using panel data (Olayungbo and Quadri, 2019). Arellano and Bond (1991) explained that pooled mean group ARDL and Generalized Method of Moments (GMM) are applicable when the number of periods exceeds the number of cross-sections, i.e. $(\mathrm{N}<\mathrm{T})$. Among the GMM and the pooled mean group or panel ARDL approach, we prefer panel ARDL approach when variables are not stationary at the same level (Im et al., 2003). Our data fulfills this condition and points towards the qualification of the panel ARDL approach. This approach allows variation in error terms and coefficients by units in the short run but assumes the coefficients identical in the long run. The panel ARDL approach also tackles residual correlations, the long-term inconsistency of the results and endogeneity problems more efficiently (Alam and Quazi, 2003). The equation 1 is the econometric description of the panel ARDL approach chosen for this study proposed by Pesaran et al. (1999) as: 


$$
\begin{aligned}
& \Delta \ln P R O D_{j, t}=\propto_{0 i}+\sum_{i=1}^{n} \propto_{1 i} \Delta \ln P R O D_{i, t-1}+\sum_{i=1}^{n} \propto_{2 i} \Delta \ln L E_{i, t-1}+ \\
& \sum_{i=1}^{n} \propto_{3 i} \Delta \ln G E_{i, t-1}+\sum_{i=1}^{n} \propto_{4 i} \Delta \ln G S_{i, t-1}+\sum_{i=1}^{n} \propto_{5 i} \Delta \ln H D I_{i, t-1}+ \\
& \sum_{i=1}^{n} \propto_{6 i} \Delta \ln C P I_{i, t-1}+\beta_{1} \ln P R O D_{j, t-1}+\beta_{2} \ln L E_{j, t-1}+\beta_{3} \ln G E_{j, t-1}+\beta_{4} \ln G S_{j, t-1}+
\end{aligned}
$$$$
\beta_{5} \ln H D I_{j, t-1}+\beta_{6} \ln C P I_{j, t-1}+\mu_{j, t}
$$

Where $P R O D$ denotes productivity, $L E$ stands for labor efficiency, $G E$ means the gross earnings, and GS represents government spending. The notation $H D I$ indicates the human development index, a measure of the quality of life used in this study, and $C P I$ represents the consumer price index, a widely used proxy for inflation. The alphas $\left(\propto_{i=1}^{6}\right)$ represent coefficients of the shortterm relationships and betas $\left(\beta_{i=1}^{6}\right)$ represent coefficients for long term relationships. The symbol $\mathrm{j}$ represents the countries, $t$ for time, and $\mu$ denotes the error term.

\section{Empirical Results}

Analyzing the time-series properties of the study variables is essential to make further statistical inferences. This research uses several unit root tests to assess whether all the variables are stationary at $I(0)$ and I(1), one of the underlying conditions for applying panel ARDL. Table 2 summarizes the unit root tests depicting the results confirmed by the majority of the criteria used.

Table 2

Results on Stationary Summarized

\begin{tabular}{|lll|}
\hline NO & Variable & Stationery \\
\hline 1 & Productivity (PROD) & $\mathrm{I}(1)$ \\
\hline 2 & Labor Efficiency (LE) & $\mathrm{I}(1)$ \\
\hline 3 & Gross Earning & $1(0)$ \\
\hline 4 & Government Spending (GS) & $\mathrm{I}(0)$ \\
\hline 5 & Human Development Index (HDI) & $\mathrm{I}(1)$ \\
\hline 6 & Inflation (CPI) & $\mathrm{I}(0)$ \\
\hline
\end{tabular}


Multiple tests like Levin et al. (2002), Im et al. (2003), along with Fischer Chi-squared tests (ADF \& PP), are applied to the data to ensure data stationary at varying levels. Summarized results based on majority acceptance criteria are reported. Among study variables, productivity (PROD), labor efficiency (LE) and human development index ( $\mathrm{HDI})$ are stationary at the level and the remaining variables including gross earnings (GE), government spending (GS) and Inflation (CPI) are stationary at the first difference. This scenario fulfills the I(0) and I(1) condition for different data series justifying the application of the panel autoregressive distributed lag (ARDL) approach on this panel data series.

Table 3

Panel ARDL Long-Run Relationship

\begin{tabular}{|llll|}
\hline Variables & Coefficient & z-value & p-value \\
\hline LE & -1.4324 & -3.42 & 0.00 \\
GE & 0.2033 & 1.01 & 0.31 \\
GS & -0.3720 & -3.05 & 0.00 \\
HDI & 3.6432 & 3.08 & 0.00 \\
CPI & -0.5715 & -2.31 & 0.02 \\
\hline
\end{tabular}

Table 3 reports the panel ARDL regression results for the study variable in the long run. The results for labor efficiency, government spending, quality of life, and inflation are significant in the long term. However, labor efficiency and government spending and inflation are negatively associated with productivity. Gross earnings per person and HDI are positively associated with productivity but the results for the gross earnings are insignificant in the long run. As expected, the results for labor efficiency are negatively associated with productivity. This study describes efficient labor as if fewer people are working a higher number of hours in a country. So, if the ratio of population to the number of hours is large, the labor is treated as inefficient. Therefore, an increase in this ratio should cause an inverse impact on productivity as depicted by a significant negative coefficient value (i.e., beta=-1.4324 \& p-value $=0.00$ ). A lower value of this ratio means higher labor efficiency and its negative influence represents more productivity. Gross earnings per person have a positive impact on national productivity but its impact found insignificant in the long run. Similar to the proposition of Butkiewicz and Yanikkaya (2011), government spending had a significant negative influence on productivity in selected European countries with a beta value of -0.3720 and a $p$-value of less than 0.00 . A better quality of life as measured through HDI depicts a significant increase in productivity in selected countries confirming the results of Rahman et al. (2020) as it had a positive coefficient value of 3.6432 at a $1 \%$ level of significance. Inflation measured through $\mathrm{CPI}$ also had a significant negative impact on productivity, confirming the previous literature. 
Table 4

Short-run relationships of countries with above-average productivity

\begin{tabular}{|c|c|c|c|c|c|c|}
\hline \multirow[t]{2}{*}{ Country } & Rank & LE & GE & GS & HDI & CPI \\
\hline & & Coefficient & Coefficient & Coefficient & Coefficient & Coefficient \\
\hline Belgium & 6 & -0.1302 & -0.1699 & -0.0385 & 2.3267 & 0.0313 \\
\hline Denmark & 5 & 0.0848 & 0.0136 & -0.0083 & 0.5624 & -0.4125 \\
\hline Germany & 9 & $-0.2260 *$ & $0.6394 * \star \star$ & -0.0023 & 0.0948 & $-0.1869 * \star \star$ \\
\hline Ireland & 4 & 0.1771 & -0.3264 & 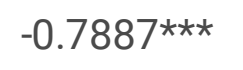 & -0.4613 & $-0.5004^{\star \star}$ \\
\hline France & 10 & $0.5112^{\star \star}$ & $1.0578 * \star \star$ & $-0.2000 * \star$ & 0.2530 & -0.0254 \\
\hline Luxembourg & 2 & 0.1450 & $0.9995^{\star}$ & -0.1170 & $2.5773^{\star \star}$ & 0.1205 \\
\hline Netherlands & 8 & -0.4466 & -0.0414 & 0.0605 & -0.7072 & -0.0896 \\
\hline Austria & 12 & -0.0488 & $0.6534^{\star *}$ & -0.0197 & 0.3589 & -0.0641 \\
\hline Finland & 11 & $-0.6694 * \star \star$ & $0.9841^{\star \star \star}$ & -0.0515 & $0.6383^{\star}$ & $0.3643^{\star \star \star}$ \\
\hline Sweden & 7 & -0.0788 & $1.1659 * \star \star$ & 0.1078 & $1.5562^{\star \star \star}$ & $0.3245^{\star \star}$ \\
\hline United Kingdom & 13 & 1.7340 ** & $0.9085^{\star \star \star}$ & -0.4276 ** & $2.3386^{\star *}$ & 0.4006 ** \\
\hline Norway & 1 & 0.2700 & $0.7683^{\star \star *}$ & $-0.5114^{\star \star \star}$ & 0.6311 & 0.0339 \\
\hline Switzerland & 3 & 0.0915 & $0.7046^{\star \star \star}$ & 0.0449 & 0.0666 & -0.2591 \\
\hline
\end{tabular}

Table 4 reports short-run panel ARDL results for 13 countries that have productivity more than the European average at the end of the study period. Results are mixed in the short run for the selected countries in this period as six countries have a negative relationship between labor efficiency and productivity. Among these six, Finland and Germany have significant results. The remaining seven had a positive impact on productivity and these results were significant only for the United Kingdom which also had the lowest productivity among selected countries as it ranked 13. A total of ten countries showed that gross earning per person had a positive impact on productivity, and these results were significant for nine countries out of ten. Remaining three countries i.e. Belgium, Ireland and the Netherlands, showed insignificant adverse effects in the short run.

The country-wise results for panel ARDL in the short-run for government spending showed that ten countries harmed productivity, and out of these ten, four countries, namely Ireland, France, the United Kingdom and Norway, had significant results. The remaining three nations had a positive but insignificant role of gross spending in defining productivity. As expected, the quality of life measured through HDI had a positive impact on productivity as confirmed by the results of eleven countries out of thirteen. Among these Luxembourg, Finland, Sweden and the United Kingdom had a significant effect on productivity. The 
only Netherlands and Ireland had a negative but insignificant impact of HDI on productivity in the short run. Out of selected countries, seven countries had a negative role of inflation in defining productivity, and out of these Germany and Ireland had significant results. Surprisingly, the results for the remaining six countries were positive, and out of these Finland, Sweden and the United Kingdom had a significant impact of CPI on productivity in the short run.

\section{Conclusions}

The research on the determinants of productivity reveals the factors that can be considered to enhance productivity in less developed countries by following the footsteps of advanced nations. This paper is another attempt to address this issue by applying more labor-intensive proxies. The analysis of data of thirteen countries with productivity levels above average in Europe for sixteen years reveals that efficient labor contributes to more productivity. Similarly, a better quality of life and average earnings of individuals in selected countries also cause an increase in productivity. Government spending and inflation cause adversity in the productivity of selected countries. These results suggest that government expenditures should be utilized more productively. These sums should also target to improve the quality of life that eventually enhances productivity. The results in the short run are not consistent across countries. This research is vital for academic uses and policy matters as well.

\section{Declarations}

\section{Competing Interests:}

There are no competing interest in this research

\section{Funding:}

Separately uploaded

\section{Author's contributions:}

First two authors primarily involved in all writings, remaining authors contributed equally.

\section{Acknowledgements:}

$\mathrm{N} / \mathrm{A}$

\section{References}


Brown K, Bradley L, Lingard H, Townsend K, Ling S (2010) Working time arrangements and recreation: making time for weekends when working long hours. Australian Bulletin of Labour 36:194.

Brown M (2012) Responses to work intensification: does generation matter? The International Journal of Human Resource Management 23:3578-3595.

Collewet M, Sauermann J (2017) Working hours and productivity. Labour economics 47:96-106.

Dias J, Tebaldi E (2012) Institutions, human capital, and growth: The institutional mechanism. Structural Change and Economic Dynamics 23:300-312.

Afonso A, Furceri D (2010) Government size, composition, volatility and economic growth. European Journal of Political Economy 26:517-532.

Romero-Avila D, Strauch R (2008) Public finances and long-term growth in Europe: Evidence from a panel data analysis. European Journal of Political Economy 24:172-191.

Adnan Z, Chowdhury M, Mallik G (2019) Foreign direct investment and total factor productivity in South Asia. Theoretical \& Applied Economics 2.

Blažys E (2020) Governance spending fixation as a tool for reform to improve institutions. Economic Research-Ekonomska Istraživanja 33:934-956.

Baharin R, Syah Aji R H, Yussof I, Mohd Saukani N (2020) Impact of Human Resource Investment on Labor Productivity in Indonesia. Iranian Journal of Management Studies 13:139-164.

Lalwani V, Chakraborty M (2020) Aggregate earnings and gross domestic product: International evidence. Applied Economics 52:68-84.

Roy S, Mohanty R (2020) Microfinance models in improving'quality of life': empirical analysis on Indian perspective. International Journal of Business Innovation and Research 21:23-55.

Bulman T, Simon J (2020) Abstract for RDP 2003-10: Productivity and Inflation.

Morvillier F (2020) Do currency undervaluations affect the impact of inflation on growth? Economic Modelling 84:275-292.

Narayan P, Smyth R (2009) The effect of inflation and real wages on productivity: new evidence from a panel of G7 countries. Applied economics 41:1285-1291.

Gujarati D (2003) Basic Econometrics Fourth Edition McGraw Hill Gujarati, DN,(2003). Basic Econometrics. McGraw Hill. International Edition.

Baltagi B (2008). Econometric analysis of panel data. John Wiley \& Sons. 
Olayungbo D, Quadri A (2019) Remittances, financial development and economic growth in sub-Saharan African countries: evidence from a PMG-ARDL approach. Financial Innovation 5:9.

Arellano M, Bond S (1991) Some tests of specification for panel data: Monte Carlo evidence and an application to employment equations. The review of economic studies 58:277-297.

Im K S, Pesaran M H, Shin Y (2003) Testing for unit roots in heterogeneous panels. Journal of econometrics 115:53-74.

Alam I, Quazi R (2003) Determinants of capital flight: An econometric case study of Bangladesh. International Review of Applied Economics 17:85-103.

Pesaran M H, Shin Y, Smith R P (1999) Pooled mean group estimation of dynamic heterogeneous panels. Journal of the American statistical Association 94:621-634.

Levin A, Lin C-F, Chu C-S J (2002) Unit root tests in panel data: asymptotic and finite-sample properties. Journal of econometrics 108:1-24.

Butkiewicz J L, Yanikkaya H (2011) Institutions and the impact of government spending on growth. Journal of Applied Economics 14:319-341.

Rahman R A, Raja M A, Ryan C (2020) The Impact of Human Development on Economic Growth: A Panel Data Approach. Available at SSRN.

\section{Supplementary Files}

This is a list of supplementary files associated with this preprint. Click to download.

- FundingDetailJEM.docx 